REVIEW

\title{
Inadequacies of glucocorticoid replacement and improvements by physiological circadian therapy
}

\author{
Miguel Debono, Richard J Ross and John Newell-Price \\ Academic Unit of Diabetes, Endocrinology and Metabolism, School of Medicine \& Biomedical Sciences, Royal Hallamshire Hospital, University of Sheffield, \\ Room OU142, O Floor, Sheffield S1O 2RX, UK
}

(Correspondence should be addressed to J Newell-Price; Email: j.newellprice@sheffield.ac.uk)

\begin{abstract}
Patients with adrenal insufficiency need lifelong glucocorticoid replacement, but many suffer from poor quality of life, and overall there is increased mortality. Moreover, it appears that use of glucocorticoids at the higher end of the replacement dose range is associated with increased risk for cardiovascular and metabolic bone disease. These data highlight some of the inadequacies of current regimes.

The cortisol production rate is estimated to be equivalent to $5.7-7.4 \mathrm{mg} / \mathrm{m}^{2}$ per day, and a major difficulty for replacement regimes is the inability to match the distinct circadian rhythm of circulating cortisol levels, which are low at the time of sleep onset, rise between 0200 and $0400 \mathrm{~h}$, peaking just after waking and then fall during the day. Another issue is that current dose equivalents of glucocorticoids used for replacement are based on anti-inflammatory potency, and few data exist as to doses needed for equivalent cardiovascular and bone effects. Weight-adjusted, thrice-daily dosing using hydrocortisone (HC) reduces glucocorticoid overexposure and represents the most refined regime for current oral therapy, but does not replicate the normal cortisol rhythm. Recently, proof-of-concept studies have shown that more physiological circadian glucocorticoid therapy using HC infusions and newly developed oral formulations of $\mathrm{HC}$ have the potential for better biochemical control in patients with adrenal insufficiency. Whether such physiological replacement will have an impact on the complications seen in patients with adrenal insufficiency will need to be analysed in future clinical trials.
\end{abstract}

European Journal of Endocrinology 160 719-729

\section{Introduction}

Patients suffering from adrenal insufficiency, whether primary or secondary, need to be on lifelong glucocorticoid replacement therapy. Population studies suggest that the incidence of adrenal insufficiency is increasing and the estimated prevalence of Addison's disease by 2030 is between 220 and 285 per million per year (1). The reported prevalence of secondary adrenal insufficiency is higher, between 300 and 450 per million, but this is likely to be an underestimate if undiagnosed hypopituitarism after brain injury is also considered (2). Despite replacement therapy, patients with adrenal insufficiency have higher mortality rates than the general population $(3,4)$, and suffer from impaired health-related quality of life (HRQOL) $(5,6)$, impaired bone health as evidenced by markers of bone turnover (7), and increased cardiovascular risk (8). The problem facing patients and clinicians is that all current therapies are inadequate since they are unable to provide appropriate physiological replacement. Hydrocortisone (HC), the generic pharmaceutical name for cortisol, is the preferred replacement therapy for these patients, although it is not available is some countries (including some within Europe) $(9,10)$. Some clinicians favour use of prednisolone or dexamethasone, with doses based on equipotent anti-inflammatory effect (11), but doses that have an equipotent effect on the cardiovascular system are not fully established. Moreover, monitoring treatment remains a challenge, and is based on clinical assessment and biochemical parameters (12-14). Recently, efforts have focused on the development of newer formulations of HC to provide circadian glucocorticoid replacement therapy aimed to imitate more closely the normal physiological cortisol rhythm (15-17).

Here, we review the morbidity and mortality associated with adrenal insufficiency. We then discuss normal physiology of cortisol secretion and illustrate how current therapies remain inadequate. Finally, we summarise the state of the art in circadian cortisol therapy, and discuss areas that need further study. 


\section{Cardiovascular mortality and morbidity}

In a recent study on 1675 patients with primary adrenal insufficiency in Scandinavia, mean age at diagnosis 37.3 years, with a follow-up period from initial diagnosis of 6.5 years, there was a mortality rate twofold higher than that of the background population (3). Deaths occurred from malignant $(n=73)$, endocrine $(n=64)$, respiratory $(n=45)$ and infectious diseases $(n=12)$, but the largest cause of death was cardiovascular disease $(n=239)$. These data have been confirmed in a very recent study involving 3299 patients with primary autoimmune adrenal failure, where the leading cause of death was cardiovascular disease (18). Similarly, patients with secondary adrenal insufficiency have excess mortality. In 333 consecutive patients with hypopituitarism diagnosed between 1956 and 1987, the overall mortality was higher than the age- and sex-matched normal population, with vascular disease accounting for 60 deaths compared with the 31 expected (19).

The important adverse effects of even modest excess glucocorticoid dosing on cardiovascular risk has been assessed in a recent large Scandinavian study in 2424 patients with hypopituitarism (20). As a group those requiring glucocorticoid replacement had a higher waist circumference, total cholesterol, serum triglycerides and HbAlc. However, in those patients who received doses of glucocorticoid equivalent to $\mathrm{HC}$ $20 \mathrm{mg} /$ day or less, metabolic end points did not differ from patients not requiring glucocorticoids. Moreover, all new cases of diabetes, stroke and myocardial infarction occurred in the glucocorticoid-treated groups. Further support for the negative effects of even low-level excess glucocorticoids comes from data studying the effects of exogenous glucocorticoids in the Scottish population, where doses of glucocorticoid above a dose equivalent of HC $30 \mathrm{mg}$ were associated with subsequent cardiovascular events, including stroke and myocardial infarction (21).

\section{Glucocorticoid replacement and glucose homeostasis}

In terms of potential mechanisms for the observed adverse effects of glucocorticoids on cardiovascular risk, it is well established that high doses of glucocorticoids cause insulin resistance and diabetes, but whether this is true for low-dose glucocorticoid replacement is still a matter for debate. In normal subjects, glucose tolerance is relatively impaired in the afternoon and evening compared with the morning (22). An immediate effect of a small rise in serum cortisol is to inhibit insulin secretion, but leave circulating glucose unchanged, while, in contrast, peaks of serum cortisol exceeding the normal daily excursions (caused by doses of HC) are associated with a reduction in insulin sensitivity, which is apparent $4-6 \mathrm{~h}$ later, and may persist for more than
$16 \mathrm{~h} \mathrm{(23).} \mathrm{This} \mathrm{is} \mathrm{illustrated} \mathrm{by} \mathrm{administration} \mathrm{of} \mathrm{oral}$ $\mathrm{HC} 50 \mathrm{mg}$; when given at $0500 \mathrm{~h}$ the delayed hyperglycaemic effect is minimal, whereas when given at $1700 \mathrm{~h}$ there is a much more pronounced increase in insulin secretion and with a 30\% decrease in insulin clearance (24). Therefore, 24-h physiological cortisol rhythmicity may be partly responsible for the normal diurnal variation in glucose tolerance and providing physiological HC replacement may be crucial to maintain the homeostasis of daily glucose control. However, when more usual replacement doses are given the data are less clear cut. On the one hand, hypopituitary patients on conventional replacement showed higher total plasma glucose and insulin when given glucocorticoid before an oral glucose tolerance test (OGTT), compared with when it was given after the OGTT, with the difference in glucose exposure correlating with the maximal cortisol level (8). On the other hand, over a 4-week observation period in patients suffering from primary adrenal insufficiency, no significant difference was observed in fasting plasma insulin, insulin resistance or $\beta$-cell function when taking either $\mathrm{HC} 10 \mathrm{mg}$ morning $/ 5 \mathrm{mg}$ mid-day or HC $10 \mathrm{mg}$ morning $/ 5 \mathrm{mg}$ mid-day/5 mg evening or dexamethasone $0.1 \mathrm{mg} / 15 \mathrm{~kg}$ body weight at breakfast, although values for the dexamethasone tended to be higher (25). Furthermore, when comparing low-dose oral HC replacement therapy $(15 \mathrm{mg}$ at $0800 \mathrm{~h}, 5 \mathrm{mg}$ at $1700 \mathrm{~h}$ ) to a physiological $\mathrm{HC}$ infusion, endogenous glucose production was similar (26). Overall, these data suggest that lower levels of glucocorticoid have fewer adverse effects, but that even modest excursions outside normal physiology cause an adverse metabolic profile.

Although it is important to debate the potential effects on the cardiovascular system of long-term overreplacement with glucocorticoids, under-replacement also needs to be avoided. In a cohort of 6107 patients with pituitary disease studied from 1963 to 1996, and providing 105797 person years of follow-up, there were 433 deaths from all causes. The overall risk of death was four times the normal population. Importantly, one of the most striking risk factors was adrenal insufficiency: out of the 35 subjects found dead or comatose by families or friends, $30(86 \%)$ probably died from unrecognised or inadequately treated adrenal insufficiency (4).

\section{Poor health-related quality of life}

HRQOL is consistently impaired in patients with Addison's disease. Scores on the SF-36 quality-of-life questionnaire in 79 patients with Addison's disease showed that general health and vitality perception were low, while total fatigue, physical fatigue and mental fatigue were all high, compared with normal (6). A significant number of patients in the 18-67 age group were out of work due to disablement, while 
HRQOL in patients on treatment was found to be comparable with that of congestive heart failure. In a survey from the Netherlands, $50 \%$ of patients with primary adrenal insufficiency considered themselves unfit to work and 30\% needed household help (27). Similar findings have been found in patients with secondary adrenal insufficiency with SF-36 scores significantly lower in seven out of eight dimensions, and significantly higher levels of anxiety and depression, compared with normal individuals (5).

Whether poor quality of life is caused by nonphysiological replacement of glucocorticoids is unknown, but published data for patients on conventional replacement therapy is that morning fatigue is a particular feature: well being is lowest just before the first dose of morning glucocorticoid, rising to a maximum at lunch time, and then falling gradually towards the evening, with HRQOL better on thrice rather than twice-daily $\mathrm{HC}$ (13). Similarly, a twice-daily regimen of $\mathrm{HC}$ appears to be better than once daily (28).

\section{Sleep disturbances}

The cortisol rhythm and the sleep-wake cycle have independent pulse generators in the suprachiasmatic nucleus $(\mathrm{SCN})$, but there is a bidirectional relationship such that any sleep-wake transitions may modulate the effects of cortisol circadian rhythmicity, and vice versa (29). At sleep onset, and during the initial hours of sleep, cortisol levels are low, a period mostly associated with slow-wave sleep (SWS), while there is a predominance of time spent in rapid eye movement (REM) sleep in the second half of the night when cortisol levels are increasing prior to and after waking. Delta wave activity (deep sleep) cannot develop unless corticotrophic activity is low; inhibition of $\mathrm{CRH}$ release results in decreased sympathetic activity and cortisol production. Increased cortisol levels at night are significantly associated with light sleep and wakefulness $(30,31)$.

The problems of sleep are illustrated in 60 patients in adrenal insufficiency, where $34 \%$ reported weekly sleep disturbances (difficulties falling asleep in 13\%; repeated awakenings in 14\%; and early morning awakenings in $20 \%$ ) (32). Early morning awakening, the most common complaint, could be related to abnormalities in the hypothalamo-pituitary-adrenal (HPA) axis despite these patients being on treatment. During daily activities, $40 \%$ of patients were tired more than once a week, but the scores of the Epworth sleepiness scale questionnaire were not higher than normal. This confirmed the presence of increased daytime fatigue in patients with Addison's disease, but no more daytime sleepiness than normal.

The effect on REM sleep has been assessed in ten HC-deprived patients with Addison's disease, where there was an increase in REM sleep latency (145 min) and diminished time spent in REM sleep, whereas HC at bedtime resulted in a REM latency of $70.7 \mathrm{~min}$ (33).
The REM latency in normal individuals is around $103 \mathrm{~min}$ (34). Moreover, the absence of HC resulted in a decrease in sleep continuity, while HC replacement resulted in a more consolidated sleep pattern. This may be related to either absolute cortisol levels or possibly to a reduction in the levels of $\mathrm{CRH}$ or ACTH. However, there is an optimum to be attained since high doses of exogenous glucocorticoids in normal individuals reduce REM sleep (35), and patients on higher doses of nocturnal glucocorticoid frequently report sleep disturbance.

Effects on SWS are variable and may be related to the dose of corticosteroids and the differential effect on binding to high-affinity mineralocorticoid receptors in the hippocampus and amygdala (CRH suppression) or low-affinity glucocorticoid receptors (GRs) in the amygdala (CRH stimulation) (31). Thus, it is possible that more physiological cortisol replacement could achieve sleep indices closer to normal values in patients with adrenal insufficiency.

\section{Defects in bone metabolism}

Bone loss secondary to suppression of osteoblastic function, evident by lower osteocalcin levels, may also occur with increasing $\mathrm{HC}$ doses. Serum osteocalcin levels significantly decrease with an increase in $\mathrm{HC}$ doses (7). In 19 patients whose mean glucocorticoid dose was reduced from 29.5 to $20.8 \mathrm{mg}$ over $\sim 3.5$ months, the median osteocalcin concentration increased significantly from 16.7 to $19.9 \mu \mathrm{g} / \mathrm{l}$. Therefore, small changes in cortisol replacement therapy may have effects on bone turnover with higher doses more likely to have an adverse effect on bone formation (36). Despite this, no specific changes have been observed in circulating bone alkaline phosphatase, another marker of bone formation, in those on glucocorticoid replacement therapy (37).

Effects on bone density (BMD) are debatable, especially as different studies have shown conflicting results. The BMD at the lumbar spine in 15 patients on glucocorticoid replacement (mean daily dose cortisone acetate $36.6 \mathrm{mg}$ ) for more than 5 years varied within the normal reference range, and also did not differ significantly from matched controls (38), with the suggestion that patients on currently recommended low-dose HC regimes do not need BMD screening. By contrast, in 91 patients with Addison's disease, who had been receiving glucocorticoid replacement therapy for an average of 10.6 years, a significant negative linear correlation was shown between HC dose per kilogram of body weight and BMD in the lumbar spine in men but not in women (39). The difference in gender could be explained by the women being pre-menopausal or post-menopausal oestrogen replacement therapy.

Circadian variation of bone remodelling is shown by levels of markers of bone resorption (urinary excretion of urinary cross-linked N-telopeptide of type 1 collagen 
(NTx) (40) and pyridinium cross-links $(41,42))$ and formation (serum osteocalcin, respectively $(43,44))$ : peak levels occur at night with a nadir in the afternoon. The levels of osteocalcin fall following the rise in serum cortisol, with a latency $\sim 4 \mathrm{~h}(45)$. Reproducing the cortisol circadian rhythm using HC infusions maintained the circadian rhythm of osteocalcin, whereas with a constant $\mathrm{HC}$ infusion the afternoon nadir of serum osteocalcin was eliminated (46). These data indicate that the circadian variation in osteocalcin is under the control of the endogenous circadian variation in serum cortisol. Thus, it is possible that circadian replacement cortisol therapy could provide a treatment that interacts with bone physiology more effectively.

Taken together, these findings suggest that patients should be maintained on the lowest possible HC replacement doses, so as to avoid impaired bone health and the likelihood of development of osteoporosis and its consequences in the long term. It is important to stress, however, that this is a recommendation based on our current knowledge, and that the influence of glucocorticoid replacement on bone health and fracture risk is not fully established, and more work is needed in this area.

\section{Normal cortisol physiology}

\section{Cortisol circadian rhythm}

Cortisol has a distinct circadian rhythm that is well established and has been analysed in fine detail (47). Cortisol reaches the lowest levels at around midnight. These then start to rise at $\sim 0200-0300 \mathrm{~h}$ and reach a peak in the morning after waking. Following this, the levels slowly decrease back to the nadir to complete the cycle over $24 \mathrm{~h}$ (48). This rhythm is characterised by a constant and reproducible pattern under stable physiological conditions (49).

The regulation of cortisol is critically determined by the activity of the HPA axis, which receives input from the central 'master' pacemaker in the SCN via the circadian release of $\mathrm{CRH}$ from the paraventricular nucleus. $\mathrm{CRH}$ release is also influenced by a wide variety of physical and emotional stressors, and in turn stimulates the release of ACTH from the corticotroph cells in the anterior pituitary (in synergy with vasopressin), and thence cortisol from the adrenal cortex. In turn, cortisol exerts inhibitory effects at pituitary and hypothalamic levels, in a classical negative feedback loop but does not seem to feedback on the SCN (50), and the GR appears to be absent in this structure.

The adrenal gland contains a circadian clock regulated via the splanchnic nerve, which defines a time window during which the adrenal most effectively responds to ACTH (51). Clock genes in the zona glomerulosa and zona fasciculata and entire metabolic pathways relevant to the adrenal gland, such as those responsive to steroid metabolism in the liver, are transcriptionally regulated by the circadian clock (52). Clock genes in the adrenal gland show a 6 -h phase delay relative to the $\operatorname{SCN}(53,54)$.

Thus, there is a tightly co-ordinated interplay between the production of glucocorticoids and the responsiveness of target tissues, which is lost in adrenal insufficiency.

\section{Cortisol production rate}

A number of cortisol secretory episodes occur during the $24 \mathrm{~h}$ of the day, making it possible to describe four different unequal temporal phases. These phases are represented by: (i) a period of minimal secretory activity, during which cortisol secretion is negligible and occurs $4 \mathrm{~h}$ before and $2 \mathrm{~h}$ after sleep onset; (ii) a preliminary nocturnal secretory episode at the 3rd to 5th hours of sleep; (iii) a main secretory phase of a series of three to five episodes occurring during the 6th to 8th hour of sleep and continuing through the 1st hour of wakefulness; and (iv) an intermittent waking secretory activity of four to nine secretory episodes found in the 2 nd to 12 th-hour waking period (47). Using stable isotopic methodology, the daily cortisol production rate is $\sim 5.7-7.4 \mathrm{mg} / \mathrm{m}^{2}$ per day or $9.5-9.9 \mathrm{mg} /$ day (55-57), less than previous estimates of $12-15 \mathrm{mg} / \mathrm{m}^{2}$ per day. Cortisol production rates in children and adolescents are very similar.

\section{Evolution of glucocorticoid replacement therapy}

It has been established for many years that adrenal insufficiency is not compatible with life (58). In 1933, initial studies on adrenalectomised dogs revealed a progressive decrease in blood volume with a progressive fall of blood pressure until death. Blood volume and blood pressure changes appeared within 24-72 h after discontinuation of injections of adrenal cortex extract, and before any symptoms of adrenal insufficiency were evident. Following administration of adequate amounts of 'cortical hormone' blood volume, blood pressure and blood constituents all returned to normal. In 1937 , 11-deoxycortisol was synthesised, and by 1940 cortisone and $\mathrm{HC}$ had been isolated by Kendall and Reichstein. The first published report of the efficacy of cortisone in the treatment of rheumatoid arthritis appeared in 1949, and had such an enormous impact on the scientific community that the Nobel Prize in Medicine was jointly awarded to Philip Hench, Edward Kendall and Tadeus Reichstein, just one year later in 1950. In that same year, George Widmer Thorn and P H Forsham were the first to use cortisone acetate in Addison's disesase, where the treatment had to be supplemented with sodium chloride or deoxycortone 
acetate to achieve a satisfactory electrolyte balance (59). In November 1950, Merck made cortisone available to physicians in the US (60). Since then patients with adrenal insufficiency have been treated with glucocorticoid, and since the introduction of fludrocortisone in the 1950s, replacement therapy has remained virtually unchanged (10).

\section{Current treatment of adrenal insufficiency}

\section{Different regimens and doses}

$\mathrm{HC}$ is now the most commonly used glucocorticoid for adrenal insufficiency. Traditionally, the dose of HC was two-thirds in the morning and one-third in the evening to try and replicate cortisol circadian rhythm, usually $20 \mathrm{mg}$ in waking and $10 \mathrm{mg}$ in the evening (61). Newer estimates of the cortisol production rate (see above) indicate that $15-20 \mathrm{mg}$ total daily $\mathrm{HC}$ is required. Unfortunately, $\mathrm{HC}$ has a short plasma half-life and patients taking this tablet wake with undetectable cortisol levels, thus achieving peak cortisol levels an hour after dosing $(14,62)$. The pharmacokinetics of $20 \mathrm{mg} \mathrm{HC}$ has been studied after i.v. and oral administration. After i.v. administration, $\mathrm{HC}$ is eliminated with a total body clearance of $18 \mathrm{l} / \mathrm{h}$ and a halflife of $1.7 \mathrm{~h}$. The volume of distribution is $34 \mathrm{l}$. Oral bioavailablity averages 96\%. This predicts very low levels of cortisol by mid-afternoon. The pharmacokinetics of immediate release HC makes it impossible for physicians to replicate physiological cortisol release. A number of research studies have explored different $\mathrm{HC}$ regimes to try and identify the best doses and patterns of treatment. Patients on a thrice-daily regimen show levels of cortisol, which are much more constant and better imitate physiological cortisol rhythm when compared with those on a twice-daily regimen (13). The use of weight-adjusted dosing before food showed decreased inter-patient variability in maximum cortisol concentration from 31 to $7 \%$, and reduced overexposure to $<5 \%$, and thrice-daily weight-adjusted dosing has been recommended as the preferred $\mathrm{HC}$ regime (14). It is a clinical experience, however, that patient compliance with thrice-daily dosing is far from absolute for many patients.

Another glucocorticoid, still preferred in some European countries, is cortisone. Originally, cortisol deficiency was more commonly treated with cortisone acetate $(25 \mathrm{mg}$ in the morning and $12.5 \mathrm{mg}$ in the evening), but this drug is now less frequently used and needs to be converted to $\mathrm{HC}$ by the enzyme $11 \beta$ hydroxysteroid dehydrogenase (11ßHSD1) type 1 to become active. On the other hand, when compared with $\mathrm{HC}$, it shows a lower serum cortisol peak and possible delayed clearance of cortisol $(63,64)$ properties that may be advantageous.
Some clinicians, more commonly in the US, have favoured use of equipotent doses of prednisolone or dexamethasone for more stable glucocorticoid effects throughout the day. Prednisolone has an intermediate duration of action and more anti-inflammatory effects than mineralocorticoid activity, while dexamethasone has no mineralocorticoid effect but mainly has antiinflammatory effects with a long half-life of 36-72 h. Once- or twice-daily dosing is used for these drugs. As they are long-acting, with more powerful effects on the GR, there is an increased risk of excess exposure that may have long-term adverse consequences. Besides, surveillance of therapy is difficult $(10,65)$. Furthermore, it is likely that the dose equivalents of glucocorticoids calculated from classical antiinflammatory experiments $(66,67)$ are not equivalent for cardiovascular effects. This may be due to the different mechanism of action of the ligand-bound GR for anti-inflammatory and metabolic effects. The classical actions of the activated GR are mediated by binding DNA in promoter regions of genes and causing either transactivation or transrepression (68). Many of the metabolic effects of glucocorticoids are mediated by these means. By contrast, many of the antiinflammatory effects of glucocorticoids are mediated by mechanisms other than DNA binding, such as sequestration of $\mathrm{NF \kappa B}$ in the cytoplasm (69). A further layer of complexity is added by wide inter-individual variability in sensitivity to glucocorticoids and even intra-individual variability in different tissues (70, 71). Part of the explanation may come from GR polymorphisms that appear to be associated with altered metabolic phenotypes $(72,73)$. Such altered sensitivity could clearly have a major impact over a lifetime of exposure in patients with adrenal insufficiency. Nevertheless, if it were possible to have confidence in the appropriate dose equivalents for the use of these synthetic glucocorticoids and if the dose could be easily varied and administered, and the effects adequately monitored, then their use may have advantages with potentially fewer daily doses.

\section{Difficulties with monitoring HC replacement}

There is no universal agreement regarding appropriate monitoring of $\mathrm{HC}$ replacement to determine the most appropriate replacement dose for individual patients. Some endocrinologists are in favour of adjusting $\mathrm{HC}$ doses guided by clinical features $(38,74)$. In 46 patients with adrenal insufficiency on a median dose of $37.5 \mathrm{mg}$ cortisone acetate, serum cortisol correlated significantly with a clinical score assessing the adequacy of replacement, but there was no significant difference between those deemed under- or over-replaced patients (38). By contrast, others advocate the use of HC day curves $(12,75)$. These are inconvenient to perform, but may have particular merit in situations where patients are on drugs that interact with $\mathrm{HC}$ through enzyme 
induction or inhibition resulting in lower or higher cortisol levels respectively (see below). A simple, practical and effective way of monitoring cortisol is to measure a single serum cortisol $4 \mathrm{~h}$ after dosing, and to compare this to a dosing nomogram that allows prediction of the cortisol and hence total cortisol exposure (14).

Urinary-free cortisol levels have been used as an indicator of overall cortisol replacement $(36,76)$. The problem with this approach is that saturation of cortisol-binding globulin is rapid after oral $\mathrm{HC}$ (77), with the free cortisol then being filtered in the kidney and the potential for spurious results. Moreover, fluctuations of cortisol throughout the day are difficult to detect and are not ideal to diagnose under replacement.

Salivary cortisol measurements have also been used to detect abnormal levels of glucocorticoids (78, 79). This is a feasible way of monitoring cortisol levels but some studies show wide inter-individual variability in plasma and salivary profiles of cortisol, and a poor correlation between salivary and plasma measurements has been shown in patients with adrenal insufficiency (80). In others, the correlation is far better and this approach used for monitoring (81).

Overall, clinical assessment of patients on glucocorticoid replacement therapy remains crucial, but the optimum means of achieving this and the optimum means of biochemical monitoring remain open for debate.

\section{Hormonal and drug interactions}

Interconversion between active cortisol and inactive cortisone is driven by the isoenzymes, $11 \beta \mathrm{HSD}$ types 1 and 2 (82). The type 1 isoenzyme expressed mainly in visceral adipose tissue, liver and gonads, converts exogenous or endogenous cortisone to cortisol, hence is essential to expose local tissues to glucocorticoids (83). The GH-IGF1 axis may inhibit $11 \beta$ HSD type 1 expression (84). GH therapy in patients with hypopituitarism on stable $\mathrm{HC}$ therapy reduces the mean cortisol peak and total cortisol exposure (85). GH therapy reduces the mean ratio of $\mathrm{Fm} / \mathrm{Em}$ (ratio of urine cortisol to cortisone metabolites) bringing patients with hypopituitarism on $\mathrm{HC}$ treatment closer to physiological glucocorticoid exposure. Mean serum cortisol levels also fall in all subjects, this finding is more significant in patients on cortisone acetate indicating that patients on this drug may be more susceptible to the effects of GH on 11ßHSD type 1 (86). Thus, caution is advised when introducing GH treatment in patients on cortisol replacement, especially if on cortisone acetate, and all should be monitored for symptoms of impending adrenal insufficiency.

Oral oestrogens increase total cortisol levels by increasing cortisol-binding globulin (CBG) levels with no effect on free cortisol levels. Transdermal oestrogens, which avoid the first-pass hepatic effect, do not significantly affect CBG levels. No change in HC doses is required for patients on oestrogen therapy, but measured total serum cortisol levels may be higher, and oestrogen needs to be stopped for 6 weeks prior to any assessment of the HPA axis, or alternatively, salivary cortisol measurements may be used (87).

Cortisol metabolism occurs principally by enzymatic reduction ( $5 \beta$-reductase, $5 \alpha$-reductase - rate limiting; $3 \alpha$-HSD) and oxidation (11ßHSD1) but also by $6 \beta-$ hydroxylation, a reaction catalysed by cytochrome P450 3A4 (88, 89). Drug-drug interactions therefore occur between glucocorticoids and drugs that induce or inhibit the activity of the CYP3A4 (90), such as anticonvulsant medication (enhanced effect and hence lower cortisol levels) or anti-retroviral medication (reduced effect and hence higher cortisol levels). Furthermore, glucocorticoids are able to induce cytochrome P450 at the pre-translational level by exerting an effect directly on hepatocytes. CYP $3 A 4$ mRNA and protein have been shown to be upregulated by exposure to dexamethasone (91-93). Close monitoring of cortisol levels is essential in these scenarios to avoid decreased or increased cortisol exposure and consequent side effects (Table 1).

\section{Circadian glucocorticoid therapy}

In patients with adrenal insufficiency, it is evident that increased mortality and morbidity are still a problem and current replacement regimes are not adequate. Studies on circadian replacement have demonstrated potential to produce better results using formulations that more closely mimic this rhythm. One option is to wake at $0300 \mathrm{~h}$ to take immediate-release $\mathrm{HC}$, a strategy that resulted in a significant improvement in $17 \mathrm{OH}$-progesterone, testosterone and individual

Table 1 Drug interactions for hydrocortisone.

Drugs that accelerate metabolism by induction of
CYP3A4
Phenobarbital
Phenytoin/fosphenytoin
Carbamazepine
Primidone
Rifampin
Rifapentine
Ethosuximide
Pioglitazone
Drugs that impair metabolism by inhibition of CYP3A4
Arepitant/fosaprepitant
Itraconazole
Ritonavir
Fluoxetine
Diltiazem
Cimetidine
Drugs that increase CBG and may falsely elevate
cortisol results
Oestrogens
Mitotane


urinary 17-ketosteroids in five patients with congenital adrenal hyperplasia (CAH). This was not achieved by giving higher or later evening doses (94). This is, however, not a practical solution for the majority of patients with adrenal insufficiency, and taking doses of longer acting glucocorticoids at night is associated with impaired sleep (35).

Physiological hormone replacement, using sustained formulations of $\mathrm{HC}$, should be the safest, most effective and practical solution. Over the past few years, interventions introducing circadian cortisol therapy, using $\mathrm{HC}$ infusions and modified-release oral formulations have shown that these treatments could imitate physiological cortisol rhythm, and hence potentially result in improved therapy for patients with adrenal insufficiency.

\section{Circadian HC infusions}

In a proof-of-concept study, circadian i.v. infusions of HC imitating the normal cortisol rhythm, delivered by a programmable pump, were used to assess whether these could improve ACTH and androgen levels in two patients with Addison's disease and two patients with $\mathrm{CAH}$ (Fig. 1). In the patients with $\mathrm{CAH}$, very high plasma ACTH and 17-hydroxyprogesterone levels were present before the morning dose and at the end of conventional $\mathrm{HC}$ treatment, in contrast to significantly lower levels of both ACTH and 17-hydroxyprogesterone after circadian infusion (17) (Fig. 2). These findings were corroborated by another study on seven patients with adrenal insufficiency, where continuous s.c. hydrocortisone infusions (CSHI) were evaluated. Morning ACTH levels were reduced from high $(>39 \mathrm{pmol} / \mathrm{l})$ to near normal levels $(<18 \mathrm{pmol} / \mathrm{l})$. The glucocorticoid dose could be reduced in most patients and all were satisfied with the treatment. All mean SF-36 scores of all subscales improved, such that two patients continued

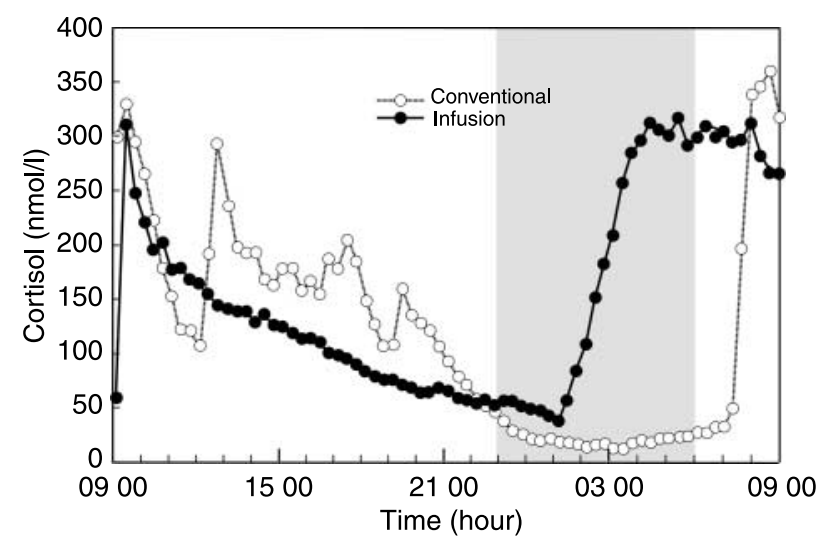

Figure 1 Comparison of mean serum cortisol levels in patients with Addison's disease and congenital adrenal hyperplasia $(\mathrm{CAH})$ during conventional oral replacement therapy and during circadian i.v. infusion of hydrocortisone (adapted from Clinical Endocrinology 2006 65: 45-50 (16)).

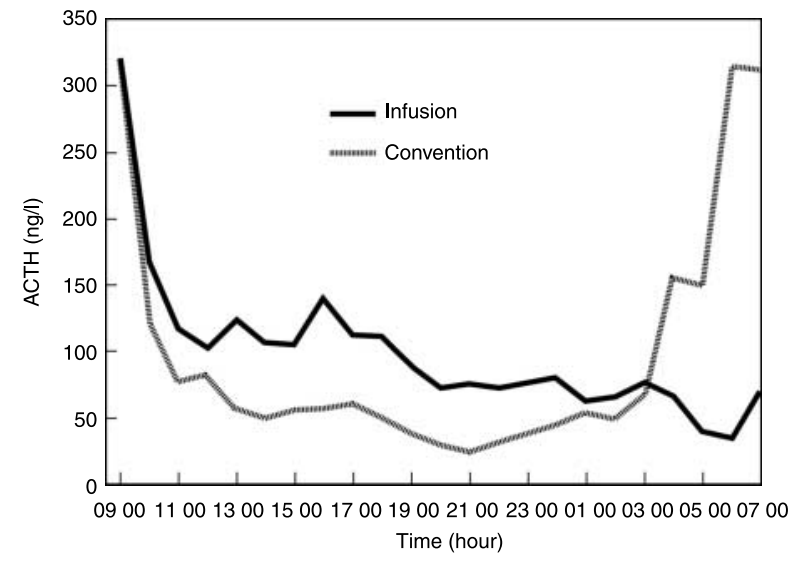

Figure 2 Comparison of mean serum ACTH levels in patients with Addison's and congenital adrenal hyperplasia (CAH) during conventional replacement therapy and during circadian infusion of hydrocortisone (to convert from $\mathrm{ng} / \mathrm{l}$ to $\mathrm{pmol} / \mathrm{l}$ : *0.22; adapted from Clinical Endocrinology 2006 65: 45-50 (16)).

CSHI permanently (95). With the caveat that these are very small, open uncontrolled studies, with the potential for a clear placebo effect, the results suggest that circadian administration of $\mathrm{HC}$ could provide better biochemical control in $\mathrm{CAH}$ and improved HRQOL in adrenal insufficiency. HC infusions are, however, very cumbersome and will not be a practical solution for the vast majority of patients. These factors have prompted the development of oral modified-release formulations.

\section{Oral delayed and sustained release formulations of HC}

One concept is to have a delayed and sustained release formulation that could be taken at night, to allow the gradual build-up of serum cortisol from 0200 to $0300 \mathrm{~h}$, and the patient to wake with physiological peak levels. The hope would be to reduce early morning fatigue in patients with adrenal insufficiency and improve biochemical control in those with $\mathrm{CAH}$. A modified-release $\mathrm{HC}$ tablet aimed at achieving these goals and consisting of an insoluble barrier coat covering all but one face of the tablet, with a slowly eroding layer retarding release from an inner drug containing layer, was tested in a pilot study of six healthy males whose endogenous cortisol had been suppressed by dexamethasone (15). The dose was administered at $2200 \mathrm{~h}$. Two formulations with predicted delayed release of 2 and $4 \mathrm{~h}$ were studied. The measured serum cortisol showed delayed release, as expected, of 2 and $4 \mathrm{~h}$, with median peak cortisol concentrations at 4.5 and $10 \mathrm{~h}$ respectively. The profiles indicated a good match to the normal circadian profile overnight, but lower cortisol levels than normal after $1200 \mathrm{~h}$ on day 2, suggesting that it would not be suitable for just once daily nocturnal dosing (Fig. 3). Thus, this formulation has the potential to achieve its 


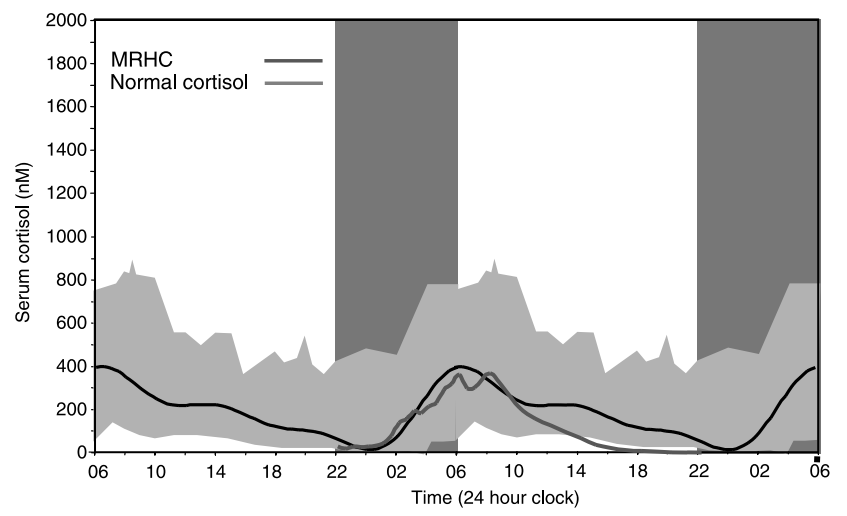

Figure 3 Concentration-time profile for modified-release hydrocortisone (MRHC), $30 \mathrm{mg}$ given at $2200 \mathrm{~h}$ showing delayed and sustained release characteristics: dark grey is mean cortisol level for subjects administered MRHC, black line is mean cortisol level in normal subjects and light grey area is range of cortisol levels in normal subjects (adapted from Clinical Endocrinology 2008 68: 130-135 (14)).

goals, but formal assessment in an appropriately designed trial in patients is needed.

Another formulation with combined immediate and extended release characteristics has also been developed (16), with the concept to allow once daily morning dosing. In a study to determine single-dose pharmacokinetics and dose proportionality, it was shown that the time to reach a clinically significant serum concentration of cortisol $(>200 \mathrm{nmol} / \mathrm{l})$ was within $25 \mathrm{~min}$ and a peak of 400-450 was obtained within 50 min after the $20 \mathrm{mg}$ tablet. Serum cortisol levels remained above $200 \mathrm{nmol} / \mathrm{l}$ for $\sim 6 \mathrm{~h}$; thereafter, whereas all serum concentrations $18-24 \mathrm{~h}$ after intake were below $50 \mathrm{nmol} / \mathrm{l}$. Thus, this has the potential for once-daily dosing, but does not address the issue for patients with adrenal insufficiency of waking with low levels of serum cortisol, although peak serum cortisol levels are achieved rapidly. These are, however, unpublished data and the full results are awaited.

In summary, these new drug delivery technologies have shown that it may be possible to simplify and improve glucocorticoid replacement, with the potential for less adverse effects and improved compliance. It is important to stress that it is yet to be established whether such therapies will result in improvements for patients with adrenal insufficiency, and clearly further studies are needed.

\section{Conclusion}

Over the past 60 years, glucocorticoid replacement therapy has had an important impact in the lives of patients with adrenal insufficiency. Yet problems remain. It is evident that although glucocorticoidrelated side effects such as increased cardiovascular risk and metabolic bone problems are less likely on low-dose $\mathrm{HC}$ replacement therapy, these may occur on higher doses. Glucocorticoid dose equivalences used by most physicians are mainly related to their anti-inflammatory effects and are not related to other therapeutic or adverse effects, and this is an area needing further investigation. Monitoring therapy and adjusting doses are problematic for all patients and physicians. Identifying biomarkers or monitoring treatment will be of the utmost importance for both clinical practice and research.

Patients with adrenal insufficiency suffer from impaired quality of life and increased mortality. Physiological, circadian cortisol replacement for these patients, while never being able to fully replicate all aspects of an intact HPA axis, offers the prospect of improved biochemical control and quality of life, and further developments and research are needed in this area.

\section{Declaration of interest}

M D \& J N-P have nothing to declare. R J R has equity interests in Diurnal Ltd.

\section{Funding}

This research did not receive any specific grant from any funding agency in the public, commercial or not-for-profit sector.

\section{References}

1 Lovas K \& Husebye ES. High prevalence and increasing incidence of Addison's disease in western Norway. Clinical Endocrinology 200256 787-791.

2 Ascoli P \& Cavagnini F. Hypopituitarism. Pituitary 20069 335-342.

3 Bergthorsdottir R, Leonsson-Zachrisson M, Oden A \& Johannsson G. Premature mortality in patients with Addison's disease: a population-based study. Journal of Clinical Endocrinology and Metabolism 200691 4849-4853.

4 Mills JL, Schonberger LB, Wysowski DK, Brown P, Durako SJ, Cox C, Kong F \& Fradkin JE. Long-term mortality in the United States cohort of pituitary-derived growth hormone recipients. Journal of Pediatrics $2004 \mathbf{1 4 4} 430-436$.

5 Hahner S, Loeffler M, Fassnacht M, Weismann D, Koschker AC, Quinkler M, Decker O, Arlt W \& Allolio B. Impaired subjective health status in 256 patients with adrenal insufficiency on standard therapy based on cross-sectional analysis. Journal of Clinical Endocrinology and Metabolism $2007923912-3922$.

6 Lovas K, Loge JH \& Husebye ES. Subjective health status in Norwegian patients with Addison's disease. Clinical Endocrinology $200256581-588$.

7 Wichers M, Springer W, Bidlingmaier F \& Klingmuller D. The influence of hydrocortisone substitution on the quality of life and parameters of bone metabolism in patients with secondary hypocortisolism. Clinical Endocrinology 199950 759-765.

8 Al-Shoumer KA, Beshyah SA, Niththyananthan R \& Johnston DG. Effect of glucocorticoid replacement therapy on glucose tolerance and intermediary metabolites in hypopituitary adults. Clinical Endocrinology $1995 \mathbf{4 2} 85-90$.

9 Arlt W \& Allolio B. Adrenal insufficiency. Lancet 2003361 1881-1893. 
10 Lovas K \& Husebye ES. Replacement therapy for Addison's disease: recent developments. Expert Opinion on Investigational Drugs 2008 17 497-509.

11 Miller WL. Clinical review 54: genetics, diagnosis, and management of 21-hydroxylase deficiency. Journal of Clinical Endocrinology and Metabolism 1994 78 241-246.

12 Howlett TA. An assessment of optimal hydrocortisone replacement therapy. Clinical Endocrinology 199746 263-268.

13 Groves RW, Toms GC, Houghton BJ \& Monson JP. Corticosteroid replacement therapy: twice or thrice daily? Journal of the Royal Society of Medicine $1988 \mathbf{8 1} 514-516$.

14 Mah PM, Jenkins RC, Rostami-Hodjegan A, Newell-Price J, Doane A, Ibbotson V, Tucker GT \& Ross RJ. Weight-related dosing, timing and monitoring hydrocortisone replacement therapy in patients with adrenal insufficiency. Clinical Endocrinology 200461 367-375.

15 Newell-Price J, Whiteman M, Rostami-Hodjegan A, Darzy K, Shalet S, Tucker GT \& Ross RJ. Modified-release hydrocortisone for circadian therapy: a proof-of-principle study in dexamethasonesuppressed normal volunteers. Clinical Endocrinology $2008 \mathbf{6 8}$ 130-135.

16 Skrtic S, Lennerräs H, Nilsson A, Bergthorsdottir R, Hedner T \& Johannsson G. Improved glucocorticoid replacement therapy by a novel oral hydrocortisone modified-release tablet (oral communication). Endocrine Abstracts 200714 OC8.6.

17 Merza Z, Rostami-Hodjegan A, Memmott A, Doane A, Ibbotson V, Newell-Price J, Tucker GT \& Ross RJ. Circadian hydrocortisone infusions in patients with adrenal insufficiency and congenital adrenal hyperplasia. Clinical Endocrinology 200665 45-50.

18 Bensing S, Brandt L, Tabaroj F, Sjoberg O, Nilsson B, Ekbom A, Blomqvist P \& Kampe O. Increased death risk and altered cancer incidence pattern in patients with isolated or combined autoimmune primary adrenocortical insufficiency. Clinical Endocrinology $200869697-704$.

19 Rosen T \& Bengtsson BA. Premature mortality due to cardiovascular disease in hypopituitarism. Lancet $1990336285-288$.

20 Filipsson H, Monson JP, Koltowska-Haggstrom M, Mattsson A \& Johannsson G. The impact of glucocorticoid replacement regimens on metabolic outcome and comorbidity in hypopituitary patients. Journal of Clinical Endocrinology and Metabolism 200691 3954-3961.

21 Wei L, MacDonald TM \& Walker BR. Taking glucocorticoids by prescription is associated with subsequent cardiovascular disease. Annals of Internal Medicine 2004141 764-770.

22 Van Cauter E, Polonsky KS \& Scheen AJ. Roles of circadian rhythmicity and sleep in human glucose regulation. Endocrine Reviews 199718 716-738.

23 Plat L, Byrne MM, Sturis J, Polonsky KS, Mockel J, Fery F \& Van Cauter E. Effects of morning cortisol elevation on insulin secretion and glucose regulation in humans. American Journal of Physiology 1996270 E36-E42.

24 Plat L, Leproult R, L'Hermite-Baleriaux M, Fery F, Mockel J, Polonsky KS \& Van Cauter E. Metabolic effects of short-term elevations of plasma cortisol are more pronounced in the evening than in the morning. Journal of Clinical Endocrinology and Metabolism 199984 3082-3092.

25 Suliman AM, Freaney R, Smith TP, McBrinn Y, Murray B \& McKenna TJ. The impact of different glucocorticoid replacement schedules on bone turnover and insulin sensitivity in patients with adrenal insufficiency. Clinical Endocrinology 200359 380-387.

26 McConnell EM, Bell PM, Ennis C, Hadden DR, McCance DR, Sheridan B \& Atkinson AB. Effects of low-dose oral hydrocortisone replacement versus short-term reproduction of physiological serum cortisol concentrations on insulin action in adult-onset hypopituitarism. Clinical Endocrinology 200256 195-201.

27 Knapen MHJM \& Puts PHM. Addison Patients in the Netherlands. Social Report of the Survey. The Hague, NL: Dutch Addison Society, 1993.
28 Riedel M, Wiese A, Schurmeyer TH \& Brabant G. Quality of life in patients with Addison's disease: effects of different cortisol replacement modes. Experimental and Clinical Endocrinology 1993 101 106-111.

29 Spath-Schwalbe E, Scholler T, Kern W, Fehm HL \& Born J. Nocturnal adrenocorticotropin and cortisol secretion depends on sleep duration and decreases in association with spontaneous awakening in the morning. Journal of Clinical Endocrinology and Metabolism 199275 1431-1435.

30 Gronfier C, Simon C, Piquard F, Ehrhart J \& Brandenberger G. Neuroendocrine processes underlying ultradian sleep regulation in man. Journal of Clinical Endocrinology and Metabolism $1999 \mathbf{8 4}$ 2686-2690.

31 Buckley TM \& Schatzberg AF. On the interactions of the hypothalamic-pituitary-adrenal (HPA) axis and sleep: normal HPA axis activity and circadian rhythm, exemplary sleep disorders. Journal of Clinical Endocrinology and Metabolism 2005 90 3106-3114.

32 Lovas K, Husebye ES, Holsten F \& Bjorvatn B. Sleep disturbances in patients with Addison's disease. European Journal of Endocrinology 2003148 449-456.

33 Garcia-Borreguero D, Wehr TA, Larrosa O, Granizo JJ, Hardwick D, Chrousos GP \& Friedman TC. Glucocorticoid replacement is permissive for rapid eye movement sleep and sleep consolidation in patients with adrenal insufficiency. Journal of Clinical Endocrinology and Metabolism 200085 4201-4206.

34 Friedman TC, Garcia-Borreguero D, Hardwick D, Akuete CN, Doppman JL, Dorn LD, Barker CN, Yanovski JA \& Chrousos GP. Decreased delta-sleep and plasma delta-sleep-inducing peptide in patients with Cushing syndrome. Neuroendocrinology 199460 626-634.

35 Born J, Spath-Schwalbe E, Schwakenhofer H, Kern W \& Fehm HL. Influences of corticotropin-releasing hormone, adrenocorticotropin, and cortisol on sleep in normal man. Journal of Clinical Endocrinology and Metabolism 198968 904-911.

36 Peacey SR, Guo CY, Robinson AM, Price A, Giles MA, Eastell R \& Weetman AP. Glucocorticoid replacement therapy: are patients over treated and does it matter? Clinical Endocrinology $1997 \mathbf{4 6}$ 255-261.

37 Valero MA, Leon M, Ruiz Valdepenas MP, Larrodera L, Lopez MB, Papapietro K, Jara A \& Hawkins F. Bone density and turnover in Addison's disease: effect of glucocorticoid treatment. Bone and Mineral 199426 9-17.

38 Arlt W, Rosenthal C, Hahner S \& Allolio B. Quality of glucocorticoid replacement in adrenal insufficiency: clinical assessment vs timed serum cortisol measurements. Clinical Endocrinology 200664 384-389.

39 Zelissen PM, Croughs RJ, van Rijk PP \& Raymakers JA. Effect of glucocorticoid replacement therapy on bone mineral density in patients with Addison disease. Annals of Internal Medicine 1994 120 207-210.

40 Ledger GA, Burritt MF, Kao PC, O'Fallon WM, Riggs BL \& Khosla S. Role of parathyroid hormone in mediating nocturnal and agerelated increases in bone resorption. Journal of Clinical Endocrinology and Metabolism $1995 \mathbf{8 0} 3304-3310$.

41 Eastell R, Simmons PS, Colwell A, Assiri AM, Burritt MF, Russell RG \& Riggs BL. Nyctohemeral changes in bone turnover assessed by serum bone Gla-protein concentration and urinary deoxypyridinoline excretion: effects of growth and ageing. Clinical Science 199283 375-382.

42 Schlemmer A, Hassager C, Jensen SB \& Christiansen C. Marked diurnal variation in urinary excretion of pyridinium cross-links in premenopausal women. Journal of Clinical Endocrinology and Metabolism 199274 476-480.

43 Nielsen HK, Brixen K, Kassem M, Charles P \& Mosekilde L. Inhibition of the morning cortisol peak abolishes the expected morning decrease in serum osteocalcin in normal males: evidence of a controlling effect of serum cortisol on the circadian rhythm in serum osteocalcin. Journal of Clinical Endocrinology and Metabolism 199274 1410-1414. 
44 Gundberg CM, Markowitz ME, Mizruchi M \& Rosen JF. Osteocalcin in human serum: a circadian rhythm. Journal of Clinical Endocrinology and Metabolism 198560 736-739.

45 Nielsen HK, Laurberg P, Brixen K \& Mosekilde L. Relations between diurnal variations in serum osteocalcin, cortisol, parathyroid hormone, and ionized calcium in normal individuals. Acta Endocrinologica 1991124 391-398.

46 Heshmati HM, Riggs BL, Burritt MF, McAlister CA, Wollan PC \& Khosla S. Effects of the circadian variation in serum cortisol on markers of bone turnover and calcium homeostasis in normal postmenopausal women. Journal of Clinical Endocrinology and Metabolism $1998 \mathbf{8 3}$ 751-756.

47 Weitzman ED, Fukushima D, Nogeire C, Roffwarg H, Gallagher TF \& Hellman L. Twenty-four hour pattern of the episodic secretion of cortisol in normal subjects. Journal of Clinical Endocrinology and Metabolism 197133 14-22.

48 Darzy KH \& Shalet SM. Absence of adrenocorticotropin (ACTH) neurosecretory dysfunction but increased cortisol concentrations and production rates in ACTH-replete adult cancer survivors after cranial irradiation for nonpituitary brain tumors. Journal of Clinical Endocrinology and Metabolism $2005905217-5225$.

49 Selmaoui B \& Touitou Y. Reproducibility of the circadian rhythms of serum cortisol and melatonin in healthy subjects: a study of three different 24-h cycles over six weeks. Life Sciences 200373 3339-3349.

50 Oster H, Damerow S, Kiessling S, Jakubcakova V, Abraham D, Tian J, Hoffmann MW \& Eichele G. The circadian rhythm of glucocorticoids is regulated by a gating mechanism residing in the adrenal cortical clock. Cell Metabolism 20064 163-173.

51 Jasper MS \& Engeland WC. Splanchnicotomy increases adrenal sensitivity to ACTH in nonstressed rats. American Journal of Physiology 1997273 E363-E368.

52 Oster H, Damerow S, Hut RA \& Eichele G. Transcriptional profiling in the adrenal gland reveals circadian regulation of hormone biosynthesis genes and nucleosome assembly genes. Journal of Biological Rhythms 200621 350-361.

53 Ishida A, Mutoh T, Ueyama T, Bando H, Masubuchi S, Nakahara D, Tsujimoto G \& Okamura H. Light activates the adrenal gland: timing of gene expression and glucocorticoid release. Cell Metabolism 20052 297-307.

54 Fahrenkrug J, Hannibal J \& Georg B. Diurnal rhythmicity of the canonical clock genes Per 1 , Per 2 and Bmal1 in the rat adrenal gland is unaltered after hypophysectomy. Journal of Neuroendocrinology 200820 323-329.

55 Kerrigan JR, Veldhuis JD, Leyo SA, Iranmanesh A \& Rogol AD. Estimation of daily cortisol production and clearance rates in normal pubertal males by deconvolution analysis. Journal of Clinical Endocrinology and Metabolism 199376 1505-1510.

56 Linder BL, Esteban NV, Yergey AL, Winterer JC, Loriaux DL \& Cassorla F. Cortisol production rate in childhood and adolescence. Journal of Pediatrics 1990117 892-896.

57 Esteban NV \& Yergey AL. Cortisol production rates measured by liquid chromatography/mass spectrometry. Steroids $1990 \mathbf{5 5}$ 152-158.

58 Swingle WW, Pfiffner JJ, Vars HM, Bott PA \& Parkins WM. The function of the adrenal cortical hormone and the cause of death from adrenal insufficiency. Science 193377 58-64.

59 Medvei VC. Present Trends and Outlook For The Future - Part III. The History of Clinical Endocrinology: A Comprehensive Account of Endocrinology from Earliest Times to the Present Day, pp 365-387. Taylor and Francis, 1993.

60 Rubin RP. A brief history of great discoveries in pharmacology: in celebration of the centennial anniversary of the founding of the American Society of Pharmacology and Experimental Therapeutics. Pharmacological Reviews 200759 289-359.

61 Besser GM \& Jeffcoate WJ. Endocrine and metabolic diseases. Adrenal diseases. BMJ 19761 448-451.

62 Derendorf H, Mollmann H, Barth J, Mollmann C, Tunn S \& Krieg M. Pharmacokinetics and oral bioavailability of hydrocortisone. Journal of Clinical Pharmacology 199131 473-476.
63 Feek CM, Ratcliffe JG, Seth J, Gray CE, Toft AD \& Irvine WJ. Patterns of plasma cortisol and ACTH concentrations in patients with Addison's disease treated with conventional corticosteroid replacement. Clinical Endocrinology 198114 451-458.

64 Nickelsen T, Schulz F \& Demisch K. Studies on cortisol substitution therapy in patients with adrenal insufficiency. Experimental and Clinical Endocrinology $1983 \mathbf{8 2} 35-41$.

65 Johannsson G, Filipsson H, Bergthorsdottir R, Lennernas H \& Skrtic S. Long-acting hydrocortisone for glucocorticoid replacement therapy. Hormone Research 200768 (Supplement 5) 182-188.

66 Dubois EF, Derks MG, Schweitzer DH, Zwinderman AH, Dekhuijzen PN \& van Boxtel CJ. Pharmacokinetic/pharmacodynamic modelling of effects of dexamethasone and prednisolone in combination with endogenous cortisol on lymphocyte counts and systemic markers of bone turn over and inflammation in healthy and asthmatic men. European Journal of Clinical Pharmacology $200460315-328$.

67 Dubois EF, Derks MG, Zwinderman AH, Dekhuijzen PN, Van Boxtel CJ \& Schweitzer DH. Distinct actions of prednisolone and dexamethasone towards osteocalcin and eosinophilic cationic protein in assumed clinically equivalent doses: a study in healthy men. European Journal of Clinical Pharmacology 2003 58 733-737.

68 Lowenberg M, Stahn C, Hommes DW \& Buttgereit F. Novel insights into mechanisms of glucocorticoid action and the development of new glucocorticoid receptor ligands. Steroids $2008 \mathbf{7 3}$ 1025-1029.

69 Reichardt HM, Tuckermann JP, Gottlicher M, Vujic M, Weih F, Angel P, Herrlich P \& Schutz G. Repression of inflammatory responses in the absence of DNA binding by the glucocorticoid receptor. EMBO Journal 200120 7168-7173.

70 Chriguer RS, Elias LL, da Silva IM Jr, Vieira JG, Moreira AC \& de Castro M. Glucocorticoid sensitivity in young healthy individuals: in vitro and in vivo studies. Journal of Clinical Endocrinology and Metabolism $2005905978-5984$.

71 Ebrecht M, Buske-Kirschbaum A, Hellhammer D, Kern S, Rohleder N, Walker B \& Kirschbaum C. Tissue specificity of glucocorticoid sensitivity in healthy adults. Journal of Clinical Endocrinology and Metabolism 200085 3733-3739.

72 van Rossum EF, Koper JW, van den Beld AW, Uitterlinden AG, Arp P, Ester W, Janssen JA, Brinkmann AO, de Jong FH, Grobbee DE, Pols HA \& Lamberts SW. Identification of the BclI polymorphism in the glucocorticoid receptor gene: association with sensitivity to glucocorticoids in vivo and body mass index. Clinical Endocrinology $200359585-592$.

73 Huizenga NA, Koper JW, De Lange P, Pols HA, Stolk RP, Burger H, Grobbee DE, Brinkmann AO, De Jong FH \& Lamberts SW. A polymorphism in the glucocorticoid receptor gene may be associated with and increased sensitivity to glucocorticoids in vivo. Journal of Clinical Endocrinology and Metabolism $1998 \mathbf{8 3}$ 144-151.

74 Oelkers W. Adrenal insufficiency. New England Journal of Medicine $19963351206-1212$.

75 Trainer PJ \& Besser GM. Barts Endocrine Protocols Edinburgh: Churchill Livingstone International, 1995.

76 Trainer PJ, McHardy KC, Harvey RD \& Reid IW. Urinary free cortisol in the assessment of hydrocortisone replacement therapy. Hormone and Metabolic Research 199325 117-120.

77 Monson JP. The assessment of glucocorticoid replacement therapy. Clinical Endocrinology $1997 \mathbf{4 6} 269-270$.

78 Patel RS, Shaw SR, McIntyre HE, McGarry GW \& Wallace AM. Morning salivary cortisol versus short Synacthen test as a test of adrenal suppression. Annals of Clinical Biochemistry $2004 \mathbf{4 1}$ 408-410.

79 Papanicolaou DA, Mullen N, Kyrou I \& Nieman LK. Nighttime salivary cortisol: a useful test for the diagnosis of Cushing's syndrome. Journal of Clinical Endocrinology and Metabolism 2002 87 4515-4521.

80 Thomson AH, Devers MC, Wallace AM, Grant D, Campbell K, Freel M \& Connell JM. Variability in hydrocortisone plasma and 
saliva pharmacokinetics following intravenous and oral administration to patients with adrenal insufficiency. Clinical Endocrinology $200766789-796$.

81 Lovas K \& Husebye ES. Salivary cortisol in adrenal diseases. Tidsskrift for Den Norske Laegeforening 2007127 730-732.

82 Stewart PM, Murry BA \& Mason JI. Human kidney 11 betahydroxysteroid dehydrogenase is a high affinity nicotinamide adenine dinucleotide-dependent enzyme and differs from the cloned type I isoform. Journal of Clinical Endocrinology and Metabolism 199479 480-484.

83 Walker BR \& Best R. Clinical investigation of 11 beta-hydroxysteroid dehydrogenase. Endocrine Research 199521 379-387.

84 Agha A \& Monson JP. Modulation of glucocorticoid metabolism by the growth hormone - IGF-1 axis. Clinical Endocrinology 200766 459-465.

85 Rodriguez-Arnao J, Perry L, Besser GM \& Ross RJ. Growth hormone treatment in hypopituitary GH deficient adults reduces circulating cortisol levels during hydrocortisone replacement therapy. Clinical Endocrinology 199645 33-37.

86 Swords FM, Carroll PV, Kisalu J, Wood PJ, Taylor NF \& Monson JP. The effects of growth hormone deficiency and replacement on glucocorticoid exposure in hypopituitary patients on cortisone acetate and hydrocortisone replacement. Clinical Endocrinology $200359613-620$.

87 Qureshi AC, Bahri A, Breen LA, Barnes SC, Powrie JK, Thomas SM \& Carroll PV. The influence of the route of oestrogen administration on serum levels of cortisol-binding globulin and total cortisol. Clinical Endocrinology 200766 632-635.

88 Tomlinson JW \& Stewart PM. Cortisol metabolism and the role of 11 beta-hydroxysteroid dehydrogenase. Best Practice and Research. Clinical Endocrinology and Metabolism 200115 61-78.
89 Waxman DJ, Lapenson DP, Aoyama T, Gelboin HV, Gonzalez FJ \& Korzekwa K. Steroid hormone hydroxylase specificities of eleven cDNA-expressed human cytochrome P450s. Archives of Biochemistry and Biophysics 1991290 160-166.

90 Flockhart DA. Drug interactions: cytochrome P450 drug interaction table. Indiana University School of Medicine, http:// medicine.iupui.edu/flockhart/table.htm, accessed 30/10/2008, 2007.

91 Watkins PB, Wrighton SA, Maurel P, Schuetz EG, Mendez-Picon G, Parker GA \& Guzelian PS. Identification of an inducible form of cytochrome P-450 in human liver. PNAS $1985826310-6314$.

92 Liddle C, Goodwin BJ, George J, Tapner M \& Farrell GC. Separate and interactive regulation of cytochrome P450 3A4 by triiodothyronine, dexamethasone, and growth hormone in cultured hepatocytes. Journal of Clinical Endocrinology and Metabolism 1998 83 2411-2416.

93 Schuetz EG, Schuetz JD, Strom SC, Thompson MT, Fisher RA, Molowa DT, Li D \& Guzelian PS. Regulation of human liver cytochromes $\mathrm{P}-450$ in family $3 \mathrm{~A}$ in primary and continuous culture of human hepatocytes. Hepatology 199318 1254-1262.

94 Moeller H. Chronopharmacology of hydrocortisone and 9 alphafluorhydrocortisone in the treatment for congenital adrenal hyperplasia. European Journal of Pediatrics 1985144 370-373.

95 Lovas K \& Husebye ES. Continuous subcutaneous hydrocortisone infusion in Addison's disease. European Journal of Endocrinology 2007157 109-112.

Received 30 December 2008

Accepted 6 January 2009 